\title{
Biology of DNMT3 and LSD1 inhibition in acute myeloid leukaemia (AML)
}

\author{
Samantha Messina* \\ Department of Human Sciences, Society and Health - University of Cassino and Southern Lazio, 03043 Cassino, Italy
}

\begin{abstract}
Epigenetic dysregulation plays a critical role in the pathogenesis of acute myeloid leukaemia (AML). The enzymes DNA methyl-transferase (DNMT3a) and Histone Lysine Demethylase (LSD1 or KDM1) are key molecules involved in transcription, DNA repair and differentiation of myeloid cells. In fact, DNMT3a is one of the most frequently mutated genes in acute myeloid leukaemia (AML) and LSD1 is essential in retinoic acid induced differentiation of myeloid cells. However, despite extensive investigation, it is not yet known their precise role in the evolution of AML clones. This information may be relevant for the successful management of the disease. In fact, it is unclear whether, mutated DNMT3a in AML clones has a dominant negative function and disrupts the formation of transcriptional complexes leading to aberrant methylation. Also, it is not known how LSD1 inhibition impacts on growth, differentiation and chemo-resistance of leukemic myeloid cells. In this review, we focus on the emerging evidences that correlate LSD1 and DNMT3a activity in acute myeloid leukaemia, their clinical relevance and how a deeper understanding of their biological function could lead to the discovery of new specific targets, some of which are currently tested in mechanism-based clinical trials.
\end{abstract}

\section{Introduction}

Acute leukaemia are clonal disorders of hematopoiesis in which leukemic stem cells (LSCs) develop unlimited self-renewal capacity, enhanced proliferation and impaired hematopoietic differentiation programs [1,2]. Recent advances in leukaemia biology come from studies that investigated on genetic and epigenetic abnormalities in leukaemic cells [3-7]. Leukaemic stem cells (LSCs) are a functionally defined multipotent entity that can undergo self-renewal, the origin of which has been the subject of considerable research in recent years. During normal developmental progression from stem cell to progenitors and then mature cells, mutations may potentially occur at any stage giving rise to a malignant entity. Both DNMT3A and LSD1 are known to regulate hematopoietic stem cell (HSC) differentiation [8]. LSD1 mediated repression of the regulatory elements of hematopoietic stem and progenitor cell (HSPC) genes is required to fully silence these genes for proper hematopoietic maturation [9], and loss of DNMT3A in HSCs results in the retention of multipotency gene expression during differentiation [10]. Inhibition of DNA methylation at PpG enhancers in LSD1 inhibitor-treated cells is likely due to its effect on DNMT3A activity. It is possible that a similar epigenetic crosstalk mechanism may regulate enhancer repression and stable silencing of multipotency genes, thus maintaining the fidelity of differentiation during hematopoiesis [11]. DNA methyl transferases and Lysine-specific histone demethylase 1 are recognized cancer targets of particular importance in the pathogenesis of acute myeloid leukaemia $[1,10,12$ 15]. Since the expression of both enzymes has been found altered mainly in hematological malignancies $[10,13,14,16-18]$, a great number of comprehensive whole genome sequencing, exome sequencing, and targeted 56 sequencing studies have been performed in AML and myeloid neoplasms in the last decade. Nevertheless, this information remains essentially descriptive [4,5,19-21]. Many of the newly identified recurrently mutated genes are involved in the epigenetic regulation of transcription [Network CGAR 2013]. Epigenetic modifiers include proteins involved in modifications of DNA cytosine residues (e.g., methylation) or post-translational modifications of histones such as methylation or acetylation. Mutations in these genes often lead directly to aberrant gene expression in AML [22]. Currently, these mutations represent a major focus of interest, and several novel epigenetic therapies are in preclinical testing phases or have entered clinical trials. In this review, we focus on recent discoveries elucidating the impact of aberrant DNA methylation and/or de-methylation on acute myeloid leukaemia with an emphasis on the role of cytosine-modifying enzymes and histone demethylase. We further discuss recent efforts to selectively inhibit these enzymes in acute myeloid leukaemia AML, which remains a deadly disease.

\section{DNMT3}

CpG methylation is mediated by a family of DNA methyltransferases (DMNTs) that regulate both maintenance (DNMT1) and de novo (DNMT3A/B) methylation in the genome [23]. During replication, DMNT1 adds methyl groups to the newly synthesized DNA strand, ensuring the preservation of DNA methylation patterns during proliferation $[24,25]$. De novo methyltransferases, DMNT3A and DMNT3B, establish new DNA methylation patterns [26]. Mutations in DNMT3A occur in 20-30\% of de novo AML patients [27-30] and often co-occur with NPM1 mutations and FLT3-ITD and confer adverse risk [29,31]. Although mutations can occur in different functional domains, almost $60 \%$ of patients display a heterozygous substitution of arginine

Correspondence to: Samantha Messina, Department of Human Sciences, Society and Health, University of Cassino and Southern Lazio, 03043 Cassino Italy, Tel: +39 0776299 3936; Fax: 0776 2993929; E-mail: samantha.messina@uniroma1.it, s.messina@unicas.it

Key words: Acute myeloid leukaemia (AML), DNA methyl-transferase (DNMT3A), lysine specific demethylase-1 31 (LSD1), epigenetics

Received: June 03, 2017; Accepted: June 20, 2017; Published: June 23, 2017 
882 in the catalytic domain that abrogates methyltransferase activity and DNA binding in vitro [6,32]. The R882 mutation in AML patients correlates with global hypomethylation, especially at CpG islands, shores and promoters [33], although promoter hypermethylation has also been described $[6,12,34]$. Mutant Dnmt3A - predominantly mutant R882 - has been shown to interact with wild-type Dnmt3A and Dnmt3B in a dominant negative manner inhibiting the wildtype methyltransferase activity of the tetrameric complex $[10,33]$. Dnmt3A is required for the normal self-renewal capacity of HSCs in adult mice and for maintaining the differentiation potential of serially transplanted HSCs in wild-type recipients [35]. Conditional deletion of DNMT3A in murine HSC causes a higher self- renewal capacity and reduced differentiation resulting in an accumulation of HSC in the bone marrow $[10,12]$. In two studies, patients with DNMT3A mutations had higher survival rates when treated with high-dose daunorubicin compared to standard-dose daunorubicin [36,37] although this has not been studied in other, well- annotated clinical trial cohorts. The effect of DNMT3a mutations in AML is elusive because AML patients with the mutant DNMT3a did not express a methylation signature that discriminates them from patients with wild-type enzyme and in many case display aberrant methylation [31,38]. Although there is a tight association between the AML patients with DNMT3a mutations and the prognosis of AML, the mechanism by which this occurs is not known yet $[27,39]$. Previous work suggested that R882 is important for the oligomerization of DNMT3A because it is located at the surface of protein- protein interaction of the enzyme, and the oligomer form of the enzyme is essential for its function [40,41]. More recently, Dnmt3a R878H conditional knockin mice revealed significant changes in gene expression and epigenetic regulatory patterns that cause differentiation arrest and growth advantage [42]. DNMT3a mutations exert a dominant negative effect because the enzyme is a tetramer and the mutated subunit may function as dominant negative variant that mislocalizes the enzyme across the genome [33].

DNMT3 Inhibitors: To date, a targeted agent is not available against DNMT3A mutations, which are thought to arise in the preleukemic hematopoietic stem cell population [43]. The DNMT inhibitors (DNMTis) azacytidine and decitabine, are generic hypomethylating agents (HMAs), nucleoside analogs that integrate into DNA and inhibit DNMTs [44]. They represent a reasonable treatment option for low blast count AML patients who are unfit for intensive induction chemotherapy with CRc rates around 20-30\% [45]. Guadecitabine (SGI-110) is a second generation HMA formulated as a dinucleotide of decitabine and deoxyguanosine, which increases the half-life of decitabine by protecting it from deamination $[46,47]$. Two studies reviewed in Saygin, et al. [48] report ongoing multicenter studies on AML patients, who were ineligible for intensive chemotherapy, no marginal difference in OS benefit [49]. A randomized phase 3 trial has been initiated to compare guadecitabine vs treatment choice (i.e., azacitidine, decitabine, or LDAC) in patients with previously untreated AML (NCT02348489). Moreover, guadecitabine has also been investigated in R/R AML patients, and a recently reported long-term 3 follow-up of phase 2 studies demonstrated a slight ameliorate [49] based on this, a phase 3 randomized, open-label study of guadecitabine vs treatment choice in R/R AML has been initiated (NCT02920008). DNA methylation profiling identified biologically distinct subtypes of AML, and certain methylation profiles were associated with adverse outcome [50,51]. Furthermore, differentially methylated regions of DNA at baseline distinguished patients who responded to HMA from non-responders in different myeloid malignancies [52,53]. Specific methylation signatures may predict responsiveness to treatment with guadecitabine and offer an opportunity to improve 1 management of elderly or R/R AML patients. Guadecitabine has demonstrated clinical activity in first-line and R/R settings, and two ongoing phase 3 studies for these patient populations may provide evidence to justify its use over LDAC and first-generation HMAs.

\section{LSD1}

FAD-dependent amine oxidase, lysine-specific demethylase 1 (LSD1) is a unique protein with the ability to catalyse the demethylation of $\mathrm{H} 3 \mathrm{~K} 4 \mathrm{me} 2$ and $\mathrm{H} 3 \mathrm{~K} 9 \mathrm{me} 2$, and therefore act as a transcriptional repressor or activator, respectively [54,55]. LSD1 was first reported to demethylate $\mathrm{H} 3 \mathrm{~K} 4 \mathrm{me} 2$ and repress transcription with the CoREST complex. However, LSD1 also catalyses the demethylation of H3K9me2 with the androgen or oestrogen receptor, and acts as a transcriptional activator [55,56]. In addition, LSD1 has since been identified in a number of activating complexes. When recruited by these complexes to target genes, LSD1 demethylates the repressive $\mathrm{H} 3 \mathrm{~K} 9 \mathrm{me} 2$ mark leading to activation of gene expression [55]. Aberrant expression of LSD1 has been shown in many types of cancers and high LSD1 expression confer poor prognosis $[15,18,57]$. The role of LSD1 is a little better understood in acute leukaemia. Particularly, in a subset of Acute Myeloid Leukaemia, LSD1 is crucial for the function and maintenance of the leukemic stem cells, a subset of malignant cells that may induce relapse in those patients. LSD1 inhibition, when coupled with all-trans retinoic acid (ATRA) therapy, induce differentiation and suppress leukaemia engraftment in AML cell lines that otherwise were insensitive to ATRA [15]. These studies provided the initial preclinical rationale to develop LSD1 inhibitors, either as monotherapy or in combination with ATRA, as a potential approach for patients with AML. Recent studies have identified a functional link between LSD1 and leukaemia maintenance. Expression analysis suggests that LSD1 might regulate a subset of genes that activate the oncogenic program associated with MLL-AF9 leukaemia and chromatin immunoprecipitation and next generation sequencing, (ChIP-Seq), showed that H3K4me2 increase is the only detectable change at MLL-AF9 promoters following LSD1 silencing. These results clearly demonstrate that in AML, demethylation by LSD1 is associated with activation of LSC associated oncogenic target genes [18]. Pharmacologic inhibition of LSD1 induced differentiation of mouse AML cells and impaired the ability of these cells to cause leukaemia in recipient mice.

LSD1 Inhibitors: Data from mouse model of AML show that co-treatment of the LSD1 inhibitor 22509 and panobinostat showed synergistic lethality of primary AML blasts and prolonged survival in xenograft AML mouse models compared to either agent alone [58]. In vitro data on IMG-98, a novel LSD1 inhibitor that irreversibly binds to LSD1's essential cofactor FAD, show that leads to its inactivated enzyme form. Exposure of AML cell lines to IMG-98 has been shown to promote differentiation and growth inhibition of AML blasts, especially in combinations with ATRA. The first clinical trials with an optimized drug closely related to IMG-98 are expected to start in early 2016. In leukaemia cell lines, there appears to be synergism between HDAC and LSD1 inhibitors which supports a clinical trial for further exploration [15]. More recently, a study describes a novel, specific, reversible lysine-specific demethylase 1 inhibitor JL1037 that induce apoptosis in cell lines as well as primary cells from AML patients [60]. Preclinical data have prompted multiple phase I trials using either irreversible LSD1 inhibitors such as GSK2879552 as a single agent or tranylcypromine in combination with ATRA (NCT02177812 and NCT02261779 at https://clinicaltrials.gov/, respectively). LSD1 is also overexpressed in solid tumors [52,57]. Given that the mechanisms by 
which LSD1 inhibition slows cancer cell proliferation remain unclear, a genetic or epigenetic signature that correlates with response would be extremely useful to help inform ongoing and future clinical trials. The selective tranylcypromine derivative LSD1 inhibitors ORY-1001 developed by Oryzon Genomics (EudraCT number 2013- 002447-29) and GSK2879552 developed by GlaxoSmithKline (NCT02177812) have entered early phase clinical trials in patients with relapsed and refractory acute leukaemia. A phase I clinical study of ATRA and tranylcypromine for adult patients with AML and MDS (NCT02273102), and a phase I/II trial of ATRA and tranylcypromine in patients with relapsed or refractory AML and no intensive treatment possibility (NCT02261779) are currently recruiting.

\section{Conclusions}

Despite significant progress in understanding the pathogenesis of AML, therapeutic options remain quite limited. DNA methyl transferases (DNMT) and Lysine-specific histone demethylase 1 (LSD1) are recognized cancer targets of particular importance in the pathogenesis of acute myeloid leukaemia. However, current pharmacological approaches are based on catalytic inhibition of these enzymes and surprisingly the molecular mechanism remains unknown. Unveiling the mechanisms of action by which these two enzymes regulate pathogenesis may be clinically relevant for the management of patients with leukaemia with poor prognosis. Further epigenetic modifiers are continuously investigated in current literature leading to sketchy data on mechanism [61]. Epigenetic treatments approved by the FDA include the DNMT inhibitors azacytidine and decitabine, non-specific hypomethylating agent. The sensitivity to this de-methylating drug is relevant, because the 5-AzadC effects on AML clones are rather heterogeneous [62] and it is not known whether DNMT3a genetic background may influence the final response to the therapy. Particularly, the prognostic importance of DNMT3A mutated gene is not clear and, to date, not defines a clinic-pathologic entity. Conversely, LSD1 has a number of substrates, including both histone and non-histone substrates $[39,42]$ and has been suggested to have multiple mechanisms of action to regulate gene expression $[54,55]$. Moreover, under many circumstances, LSD1 inhibitors alone only have minimal to modest therapeutic efficacies, which are greatly enhanced in combination with other therapies [18].

Pre-clinical studies have suggested that combination therapies of two or more epigenetic drugs, or a combination of an epigenetic drug combined with a kinase inhibitor, may have additional synergistic effects. Critical ongoing efforts include further accurate pre-clinical models to elucidate how mutations in epigenetic modifiers interact with other AML disease alleles, and clinical studies to assess the efficacy of epigenetic therapies alone or in combination with other antileukemic agents. It is unlikely that any single approach employing the agents described above, including the most targeted, will be successful in eradicating AML cells due to the related problems of intrinsic or acquired forms of resistance [63]. Indeed, dual inhibition of DNMTs and LSD1 in acute myeloid leukaemia by synergistic re-activation of epigenetically silenced genes has been reported [64]. Moreover, the speculation that the LSD1 inhibition suppress DNMT3A activity is supported by fluorescence polarization and isothermal titration calorimetry experiments $[52,65]$ Work by Petell and coworkers shows that LSD1-facilitated interaction of Dnmt3a with histone tails, which is reduced by LSD1 inhibitor treatment [11]. An innovative approach could interfere effectively without blocking the target enzymatic activity by using peptide against specific region of the two enzymes to provide novel, specific, low-toxicity treatment agents to supplement current reatment protocols [66-84].

\section{References}

1. Döhner H, Weisdorf DJ, Bloomfield CD (2015) Acute Myeloid Leukaemia. N Engl J Med 373: 1136-1152.[Crossref]

2. Kim TK, Gore SD, Zeidan AM (2015) Epigenetic Therapy in Acute Myeloid Leukaemia: Current and Future Directions. Semin Hematol 52: 172-183. [Crossref]

3. Vu LP, Luciani L, Nimer SD (2013) Histone-modifying enzymes: their role in the pathogenesis of acute leukaemia and their therapeutic potential. Int J Hematol 97: 198209.[Crossref]

4. Vidal E, Sayols S, Moran S, et al. (2017) A DNA methylation map of human cancer at single base-pair resolution. Oncogene.[Crossref]

5. Wilop S, Fernandez AF, Jost E, Herman JG, Brümmendorf TH, et al. (2011) Arraybased DNA methylation profiling in acute myeloid leukaemia. Br J Haematol 155: 65-72.[Crossref]

6. Yan XJ, Xu J, Gu ZH, Pan CM, Lu G, et al. (2011) Exome sequencing identifies somatic mutations of DNA methyltransferase gene DNMT3A in acute monocytic leukaemia Nat Genet 43: 309-315. [Crossref]

7. Silva P, Neumann M, Schroeder MP (2017) Acute myeloid leukaemia in the elderly is characterized by a distinct genetic and epigenetic landscape. Leukaemia.[Crossref]

8. Sharma, Gurudutta G (2016) Epigenetic Regulation of Hematopoietic Stem Cells. Int J Stem Cells 9: 36-43.[Crossref]

9. Kerenyi MA, Shao Z, Hsu YJ, Guo G, Luc S, et al. (2013) Histone demethylase Lsd1 represses hematopoietic stem and progenitor cell signatures during blood cell maturation. Elife2: e00633.[Crossref]

10. Challen GA (2017) Dominating the Negative: How DNMT3A Mutations Contribute to AML Pathogenesis. Cell Stem Cell 20: 7-8.[Crossref]

11. Petell CJ, Alabdi L, He M, San Miguel P, Rose R, et al. (2016) An epigenetic switch regulates de novo DNA methylation at a subset of pluripotency gene enhancers during embryonic stem cell differentiation. Nucleic Acids Res 44: 7605-7617.[Crossref]

12. Challen GA, Sun D, Jeong M, Luo M, Jelinek J, et al. (2012) Dnmt3a is essential for hematopoietic stem cell differentiation. Nat Genet 44:23-31.

13. Chaudry SF, Chevassut TJ (2017) Epigenetic Guardian: A Review of the DNA Methyltransferase DNMT3A in Acute Myeloid Leukaemia and Clonal Haematopoiesis. Biomed Res Int 2017: 5473197.[Crossref]

14. Spencer DH, Russler-Germain DA, Ketkar S, Helton NM, Lamprecht TL, et al. (2017) CpG Island Hypermethylation Mediated by DNMT3A Is a Consequence of AML Progression. Cell168: 801-816.[Crossref]

15. Schenk T, Chen WC, Göllner S, Howell L, Jin L, et al. (2012) Inhibition of the LSD1 (KDM1A) demethylase reactivates the all-trans-retinoic acid differentiation pathway in acute myeloid leukaemia. Nat Med 18: 605-611.[Crossref]

16. Bullinger L, Döhner K, Döhner H (2017) Genomics of Acute Myeloid Leukaemia Diagnosis and Pathways. J Clin Oncol 35: 934-946.[Crossref]

17. Ferreira HJ, Heyn H, Vizoso M, Moutinho C, Vidal E, et al. (2017) DNMT3A mutations mediate the epigenetic reactivation of the leukemogenic factor MEIS1 in acute myeloid leukaemia. Oncogene.[Crossref]

18. Harris WJ, Huang X, Lynch JT, Spencer GJ, Hitchin JR, et al. (2012) The histone demethylase KDM1A sustains the oncogenic potential of MLL-AF9 leukaemia stem cells. Cancer Cell 21: 473-487.[Crossref]

19. Cancer Genome Atlas Research Network, Ley TJ, Miller C, Ding L, Raphael BJ, et al (2013) Genomic and epigenomic landscapes of adult de novo acute myeloid leukaemia. N Engl J Med 368: 2059-2074.[Crossref]

20. Klutstein M, Nejman D, Greenfield R, Cedar H (2016) DNA Methylation in Cancer and Aging. Cancer Res 76: 3446-3450.[Crossref]

21. Alvarez S, Suela J, Valencia A, Fernández A, Wunderlich M, et al. (2010) DNA methylation profiles and their relationship with cytogenetic status in adult acute myeloid leukaemia. PLoS One 5: e12197.[Crossref]

22. Vianello P, Botrugno OA, Cappa A, Dal Zuffo R, Dessanti P, et al. (2016) Discovery of a Novel Inhibitor of Histone Lysine-Specific Demethylase 1A (KDM1A/LSD1) as Orally Active Antitumor Agent. J Med Chem 59: 1501-1517.[Crossref]

23. Bestor TH (1988) Cloning of a mammalian DNA methyltransferase. Gene 74: 9-12. [Crossref] 
24. Schermelleh L, Haemmer A, Spada F, Rösing N, Meilinger D, et al. (2007) Dynamics of Dnmt1 interaction with the replication machinery and its role in postreplicative maintenance of DNA methylation. Nucleic Acids Res 35: 4301-4312.[Crossref]

25. Valinluck V, Sowers LC (2007) Endogenous cytosine damage products alter the site selectivity of human DNA maintenance methyltransferase DNMT1. Cancer Res 67: 946-950.[Crossref]

26. Lei H, Oh SP, Okano M, Jüttermann R, Goss KA, et al. (1996) De novo DNA cytosine methyltransferase activities in mouse embryonic stem cells. Development 122: 31953205.[Crossref]

27. Ley TJ, Ding L, Walter MJ, McLellan MD, Lamprecht T, et al. (2010) DNMT3A mutations in acute myeloid leukaemia. $N$ Engl J Med 363: 2424-2433.[Crossref]

28. Thol F, Damm F, Lüdeking A, Winschel C, Wagner K, et al. (2011) Incidence and prognostic influence of DNMT3A mutations in acute myeloid leukaemia. J Clin Oncol 29: 2889-2896.[Crossref]

29. Marcucci G, Metzeler KH, Schwind S, Becker H, Maharry K, et al. (2012) Age-related prognostic impact of different types of DNMT3A mutations in adults with primary cytogenetically normal acute myeloid leukaemia. J Clin Oncol 30: 742-750.[Crossref]

30. Guillamot M, Cimmino L, Aifantis I (2016) The Impact of DNA Methylation in Hematopoietic Malignancies. Trends Cancer 2: 70-83.[Crossref]

31. Ribeiro AF, Pratcorona M, Erpelinck-Verschueren C, Rockova V, Sanders M, et al. (2006) Mutant DNMT3A: a marker of poor prognosis in acute myeloid leukaemia. Blood 119: 5824-5831.

32. Gowher H, Loutchanwoot P, Vorobjeva O, Handa V, Jurkowska RZ, et al. (2006) Mutational analysis of the catalytic domain of the murine Dnmt3a DNA-(cytosine C5)methyltransferase. J Mol Biol 357: 928-941.[Crossref]

33. Russler-Germain DA, Spencer DH, Young MA, Lamprecht TL, Miller CA, et al. (2014) The R882H DNMT3A mutation associated with AML dominantly inhibits wild-type DNMT3A by blocking its ability to form active tetramers. Cancer Cell 25: 442-454.

34. Qu Y, Lennartsson A, Gaidzik VI, Deneberg S, Karimi M, et al. (2014) Differential methylation in CN-AML preferentially targets non-CGI regions and is dictated by DNMT3A mutational status and associated with predominant hypomethylation of HOX genes. Epigenetics 9: 1108-1119.[Crossref]

35. Tadokoro Y, Ema H, Okano M, Li E, Nakauchi H (2007) De novo DNA methyltransferase is essential for self-renewal, but not for differentiation, in hematopoietic stem cells. $J$ Exp Med 204: 715-722.[Crossref]

36. Patel JP, Gönen M, Figueroa ME, Fernandez H, Sun Z, et al. (2012) Prognostic relevance of integrated genetic profiling in acute myeloid leukaemia. $N$ Engl $J$ Med 366: 1079-1089.[Crossref]

37. Sehgal AR, Gimotty PA, Zhao J, Hsu JM, Daber R, et al. (2015) DNMT3A Mutational Status Affects the Results of Dose-Escalated Induction Therapy in Acute Myelogenous Leukaemia. Clin Cancer Res 21: 1614-1620. [Crossref]

38. Schoofs T, Berdel WE, Müller-Tidow C (2014) Origins of aberrant DNA methylation in acute myeloid leukaemia. Leukaemia 28: 1-14.

39. Huang X, Ma D, Dong W, Li P, Lu T, et al. (2013) Gene expression profiling of the DNMT3A R882 mutation in acute leukaemia. Oncol Lett 6: 268-274.[Crossref]

40. Guo X, Wang L, Li J, Ding Z, Xiao J, et al. (2015) Structural insight into autoinhibition and histone H3-induced activation of DNMT3A. Nature 517: 640-644.[Crossref]

41. Li Y, Zhu B (2014) Acute myeloid leukaemia with DNMT3A mutations. Leuk Lymphoma 55: 2002-2012.[Crossref]

42. Dai YJ, Wang YY, Huang JY, Xia L, Shi XD, et al. (2017) Conditional knockin of Dnmt3a R878H initiates acute myeloid leukaemia with mTOR pathway involvement. Proc Natl Acad Sci U S A 114: 5237-5242.[Crossref]

43. Shlush LI, Zandi S, Mitchell A, Chen WC, Brandwein JM, et al. (2014) Identification of pre-leukaemic haematopoietic stem cells in acute leukaemia. Nature 506: 328-333. [Crossref]

44. Stresemann C, Lyko F (2008) Modes of action of the DNA methyltransferase inhibitors azacytidine and decitabine. Int J Cancer 123: 8-13.[Crossref]

45. Podoltsev NA, Stahl M, Zeidan AM, Gore SD (2017) Selecting initial treatment of acute myeloid leukaemia in older adults. Blood Rev 31: 43-62.[Crossref]

46. Issa JP, Roboz G, Rizzieri D, Jabbour E, Stock W, et al. (2015) Safety and tolerability of guadecitabine (SGI-110) in patients with myelodysplastic syndrome and acute myeloid leukaemia: a multicentre, randomised, dose-escalation phase 1 study. Lancet Oncol 16: 1099-1110.[Crossref]
47. Stein EM, Tallman MS (2016) Emerging therapeutic drugs for AML. Blood 127: 71-78. [Crossref]

48. Saygin C, Carraway HE (2017) Emerging therapies for acute myeloid leukaemia. $J$ Hematol Oncol 10: 93.[Crossref]

49. Daver N KH, Roboz GJ, Kropf PL, Yee KW, O’Connell CL, et al. (2016) Long term survival and clinical complete responses of various prognostic subgroups in $103 \mathrm{relapsed} / \mathrm{refractory}$ acute myeloid leukaemia ( $\mathrm{r} / \mathrm{r}$ AML) patients treated with guadecitabine (SGI-110) in phase 2 studies. Blood suppl: abstract 904.

50. Figueroa ME, Abdel-Wahab O, Lu C, Ward PS, Patel J, et al. (2010) Leukemic IDH1 and IDH2 mutations result in a hypermethylation phenotype, disrupt TET2 function, and impair hematopoietic differentiation. Cancer Cell 18: 553-567.[Crossref]

51. Figueroa ME, Lugthart S, Li Y, Erpelinck-Verschueren C, Deng X, et al. (2010) DNA methylation signatures identify biologically distinct subtypes in acute myeloid leukaemia. Cancer Cell 17: 13-27.[Crossref]

52. Noh KM, Wang H, Kim HR, Wenderski W, Fang F, et al. (2015) Engineering of a Histone-Recognition Domain in Dnmt3a Alters the Epigenetic Landscape and Phenotypic Features of Mouse ESCs. Mol Cell 59: 89-103.[Crossref]

53. Traina F, Visconte V, Elson P, Tabarroki A, Jankowska AM, et al. (2014) Impact of molecular mutations on treatment response to DNMT inhibitors in myelodysplasia and related neoplasms. Leukaemia 28: 78-87.[Crossref]

54. Shi Y, Lan F, Matson C, Mulligan P, Whetstine JR, et al. (2004) Histone demethylation mediated by the nuclear amine oxidase homolog LSD1. Cell 119: 941-953.[Crossref]

55. Metzger E, Wissmann M, Yin N, Müller JM, Schneider R, et al. (2005) LSD1 demethylates repressive histone marks to promote androgen-receptor-dependent transcription. Nature 437: 436-439.[Crossref]

56. Lim S, Janzer A, Becker A, Zimmer A, Schüle R, et al. (2010) Lysine-specific demethylase 1 (LSD1) is highly expressed in ER-negative breast cancers and a biomarker predicting aggressive biology. Carcinogenesis 31: 512-520.[Crossref]

57. Lv T, Yuan D, Miao X, Lv Y, Zhan P, et al. (2012) Over-expression of LSD1 promotes proliferation, migration and invasion in non-small cell lung cancer. PLoS One 7: e35065.[Crossref]

58. Fiskus W, Sharma S, Shah B, Portier BP, Devaraj SG, et al. (2014) Highly effective combination of LSD1 (KDM1A) antagonist and pan-histone deacetylase inhibitor against human AML cells. Leukaemia 28: 2155-2164.[Crossref]

59. Ramirez L, Singh M, Chandra J. HDAC and LSD1 inhibitors synergize to induce cell death in 370 acute leukaemia cells. Blood 118:620.

60. Liu S, Lu W, Li S, Li S, Liu J, et al. (2017) Identification of JL1037 as a novel, specific, reversible lysine-specific demethylase 1 inhibitor that induce apoptosis and autophagy of AML cells. Oncotarget 8: 31901-31914.[Crossref]

61. Singh Nanda J, Kumar R, Raghava GP (2016) dbEM: A database of epigenetic modifiers curated from cancerous and normal genomes. Sci Rep 6: 19340.[Crossref]

62. Tenti E, Papayannidis C, Marconi G, Parisi S, Simonetti G, et al. (2016) Efficacy of Azacitidine in the treatment of adult patients aged 65 years or older with AML. Expert Opin Pharmacother 17: 2479-2486.[Crossref]

63. Hackl H, Astanina K, Wieser R (2017) Molecular and genetic alterations associated with therapy resistance and relapse of acute myeloid leukaemia. J Hematol Oncol 10: 51.[Crossref]

64. Han H, Yang X, Pandiyan K, Liang G (2013) Synergistic re-activation of epigenetically silenced genes by combinatorial inhibition of DNMTs and LSD1 in cancer cells. PLoS One 8: e75136.[Crossref]

65. Ooi SK, Qiu C, Bernstein E, Li K, Jia D, et al. (2007) DNMT3L connects unmethylated lysine 4 of histone H3 to de novo methylation of DNA. Nature 448: 714-717.[Crossref]

66. Derissen EJ, Beijnen JH, Schellens JH (2013) Concise drug review: azacitidine and decitabine. Oncologist 18: 619-624.[Crossref]

67. Guryanova OA, Shank K, Spitzer B, Luciani L, Koche RP, et al. (2016) DNMT3A mutations promote anthracycline resistance in acute myeloid leukaemia via impaired nucleosome remodeling. Nat Med 22: 1488-1495.[Crossref]

68. Koshiba H (1975) [Comparison of drug effects on the isolated rat colon and duodenum] Nihon Yakurigaku Zasshi 71: 415-426.[Crossref]

69. Kropf P, Jabbour E, Yee K, Casey O'Connell, Tibes R, et al. (2015) Late responses and overall survival (OS) from long term follow up of a randomized phase 2 study of SGI110 (guadecitabine) 5-day regimen in elderly AML who are not eligible for intensive chemotherapy. In: 20th Congress of the European Hematology. 
70. Lim S, Janzer A, Becker A, Zimmer A, Schüle R, et al. (2010) Lysine-specific demethylase 1 (LSD1) is highly expressed in ER-negative breast cancers and a biomarker predicting aggressive biology. Carcinogenesis 31: 512-520.[Crossref]

71. Lokken AA, Zeleznik-Le NJ (2012) Breaking the LSD1/KDM1A addiction: therapeutic targeting of the epigenetic modifier in AML. Cancer Cell 21: 451-453.[Crossref]

72. Muvarak NE, Chowdhury K, Xia L, Robert C, Choi EY, et al. (2016) Enhancing the Cytotoxic Effects of PARP Inhibitors with DNA Demethylating Agents - A Potential Therapy for Cancer. Cancer Cell 30: 637-650.[Crossref]

73. Nomoto M, Yamaguchi R, Kohno K, Kasai H (2002) Relations between clusters of oxidatively damaged nucleotides and active or open nucleosomes in the rat Nth 1 gene. Oncogene 21: 1649-1657.

74. Okano M, Xie S, Li E (1998) Cloning and characterization of a family of novel mammalian DNA (cytosine-5) methyltransferases. Nat Genet 19: 219-220.[Crossref]

75. Przespolewski A, Wang ES (2016) Inhibitors of LSD1 as a potential therapy for acute myeloid leukaemia. Expert Opin Investig Drugs 25: 771-780.[Crossref]

76. Rau RE, Rodriguez BA, Luo M, Jeong M, Rosen A, et al. (2016) DOT1L as a therapeutic target for the treatment of DNMT3A-mutant acute myeloid leukaemia. Blood 128: 971-981.[Crossref]

77. Ribeiro AF, Pratcorona M, Erpelinck-Verschueren C, Rockova V, Sanders M, et al.
(2012) Mutant DNMT3A: a marker of poor prognosis in acute myeloid leukaemia. Blood 119: 5824-5831.[Crossref]

78. Saunthararajah Y (2013) Key clinical observations after 5-azacytidine and decitabine treatment of myelodysplastic syndromes suggest practical solutions for better outcomes. Hematology Am Soc Hematol Educ Program 2013: 511-521.[Crossref]

79. Shafer D, Grant S (2016) Update on rational targeted therapy in AML. Blood Rev 30 : 275-283.[Crossref]

80. Sugino N, Kawahara M, Tatsumi G, Kanai A (2017) A novel LSD1 inhibitor NCD38 ameliorates MDS-related leukaemia with complex karyotype by attenuating leukaemia programs via activating super-enhancers. Leukaemia.[Crossref]

81. Wu F, Zhou C, Yao Y, Wei L, Feng Z, et al. (2016) 3-(Piperidin-4-ylmethoxy)pyridine Containing Compounds Are Potent Inhibitors of Lysine Specific Demethylase 1. J Med Chem 59: 253-263.[Crossref]

82. Yang L, Liu Y, Zhang N, Ding X, Zhang W, et al. (2017) Novel impact of the DNMT3A R882H mutation on GSH metabolism in a K562 cell model established by TALENs. Oncotarget 8: 30395-30409.[Crossref]

83. Yang L, Rau R, Goodell MA3 (2015) DNMT3A in haematological malignancies. Nat Rev Cancer 15: 152-165.[Crossref]

84. Yang L, Rodriguez B, Mayle A, Park HJ, Lin X, et al. (2016) DNMT3A Loss Drives Enhancer Hypomethylation in FLT3-ITD-Associated Leukaemias. Cancer Cell 30: 363-365.

Copyright: (2017 Messina S. This is an open-access article distributed under the terms of the Creative Commons Attribution License, which permits unrestricted use, distribution, and reproduction in any medium, provided the original author and source are credited. 